\title{
Suplementação com zinco e selênio em frangos de corte submetidos a estresse cíclico de calor ${ }^{1}$
}

\author{
Graciele Cristina Silva ${ }^{2}$, Mara Regina Bueno de Mattos Nascimento*3, Nilson Penha-Silva ${ }^{4}$, \\ Evandro de Abreu Fernandes ${ }^{3}$, Daniela Reis Vilela ${ }^{5}$, Milena Maia Souto ${ }^{6}$
}

http://dx.doi.org/10.1590/0034-737X201562040006

\begin{abstract}
RESUMO
Frangos criados sob estresse de calor (EC) podem ter padrão antioxidante reduzido, e, a suplementação de zinco e selênio podem amenizar este efeito. Assim sendo, o objetivo deste trabalho foi avaliar os efeitos da suplementação de zinco e de selênio, nas formas orgânica e inorgânica, sobre o desempenho, a peroxidação lipídica e o rendimento de carcaça em frangos submetidos a estresse cíclico de calor (EC). Para isso, foram utilizados 2.400 pintos machos de um dia de idade, criados em conforto térmico até o $14^{\circ}$ dia, quando 1200 foram submetidos a EC. O delineamento foi o inteiramente casualizado em arranjo fatorial 2 × 5 , sendo dois ambientes [conforto (C) e estresse de calor EC] e cinco níveis de suplementação: [S1) ração controle; S2) S1 + 40 mg/kg de Zn inorgânico; S3) S1 + $40 \mathrm{mg} / \mathrm{kg}$ de Zn orgânico; S4) de S1 + $40 \mathrm{mg} / \mathrm{kg}$ de Zn inorgânico e 0,2 mg/kg de selênio orgânico, e S5) S1 + 40 $\mathrm{mg} / \mathrm{kg}$ de $\mathrm{Zn}$ orgânico e $0,2 \mathrm{mg} / \mathrm{kg}$ de selênio orgânico], totalizando dez tratamentos, com oito repetições de 30 aves cada. Foram avaliados os níveis sanguíneos de substâncias reativas ao ácido tiobarbitúrico, temperatura cloacal (TC), ganho de peso, consumo de ração, conversão alimentar, peso vivo e rendimento de carcaça e cortes. No $35^{\circ} \mathrm{e}$ no $42^{\circ}$ dias, aves sob EC apresentaram elevação de TC. Ganho de peso, conversão alimentar e carcaça eviscerada foram influenciados negativamente pelo calor. $\mathrm{O}$ ambiente e os níveis de suplemento não alteraram o rendimento de peito com e sem osso, sobrecoxa e coxa, e asas. Nas condições ambientais e nutricionais, não se identificou a necessidade de adição suplementar de zinco orgânico e inorgânico e selênio orgânico.
\end{abstract}

Palavras-chave: aves, rendimento de carcaça, desempenho, minerais, peroxidação lipídica, TBARS, temperatura cloacal.

\section{ABSTRACT}

Effects of zinc and selenium supplementation on broilers subjected to cyclic heat stress

Broilers raised under heat stress can have reduced antioxidant standard, however supplementation with zinc and selenium can mitigate this effect.In this study, we evaluated the effects of zinc and selenium supplementation, in the organic and inorganic forms, on performance, lipid peroxidation and carcass yield of broilers subjected to cyclic heat stress (HS). A total of 2400 one-day-old male chicks were raised in thermal comfort until the $14^{\text {th }}$ day, then 1200 chicks were subjected to HS. The experiment was arranged in a completely randomized design in a $2 \times 5$ factorial with 2 environmental conditions [comfort (C) and HS] and 5 supplementation levels [S1) control diet; S2) $\mathrm{S} 1+40 \mathrm{mg} / \mathrm{kg}$ of inorganic Zn; S3) S1 + $40 \mathrm{mg} / \mathrm{kg}$ of organic Zn; S4) S1 + $40 \mathrm{mg} / \mathrm{kg}$ of inorganic Zn and $0.2 \mathrm{mg}$ / $\mathrm{kg}$ organic selenium and S5) S1 $+40 \mathrm{mg} / \mathrm{kg}$ of organic $\mathrm{Zn}$ and $0.2 \mathrm{mg} / \mathrm{kg}$ selenium organic], totalling 10 treatments with 8 replicates of 30 birds each. The variables evaluated were blood levels of thiobarbituric acid

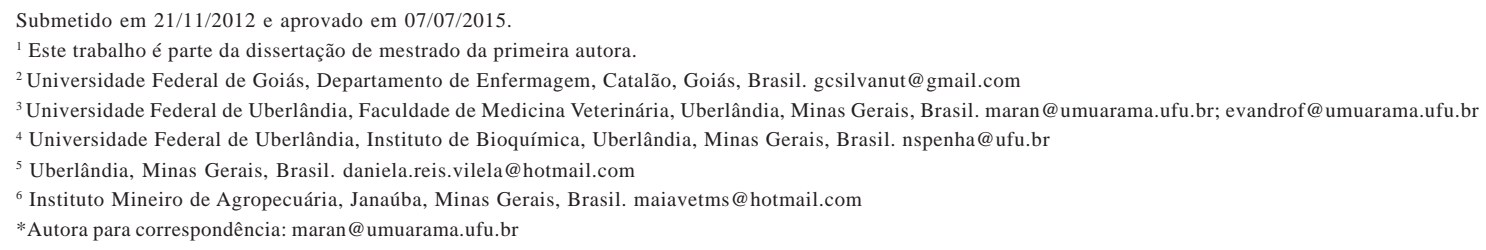


reactive substances (TBARS), cloacal temperature (CT), weight gain, feed intake, feed conversion, live weight and carcass yield and cuts. On the $35^{\text {th }}$ and $42^{\text {nd }}$ days, HS broilers showed increased cloacal temperature. Weight gain, feed conversion and eviscerated carcass were negatively influenced by heat. Environment and supplement levels did not affect breast meat yield with and without bone, drumstick, thigh, and wing. In the environmental and nutritional conditions of this study, there was no need for supplemental addition of organic and inorganic zinc and organic selenium.

Key words: poultry, carcass yield, performance, minerals, lipidic peroxidation, TBARS, body temperature.

\section{INTRODUÇÃO}

A seleção genética do frango de corte para crescimento rápido trouxe avanços no seu desempenho; entretanto, tornou esta ave menos tolerante ao calor. A redução da tolerância de frangos de corte ao estresse pelo calor tem sido um problema, especialmente, em países tropicais. Altas temperaturas e umidade do ar prejudicam o desempenho destas aves, o que resulta em crescimento reduzido e baixo peso à idade de abate. Além disso, pode causar aumento da temperatura retal, da frequência respiratória e da taxa de mortalidade (Borges et al., 2003; Hellmeister Filho et al., 2003, Marchini et al., 2011).

O estresse também reduz o padrão antioxidante, com menores concentrações de vitaminas e minerais, especialmente zinco (Sahin et al., 2009). Este mineral é um componente estrutural e catalítico da enzima antioxidante superóxido dismutase (SOD). Assim sendo, a suplementação desse mineral tem sido usada com a finalidade de amenizar os efeitos do estresse de calor.

Outro micronutriente essencial para o organismo é o Selênio $\left(\mathrm{Se}^{+2}\right)$ que induz à biossíntese da Se-glutation peroxidase $\left(\mathrm{GPx}^{\text {ase }}\right)$, a enzima mais conhecida no que se refere à estrutura e função (Daniels, 1996). Ela funciona como um antioxidante primário e é um importante componente na proteção contra os metabólitos reativos do oxigênio (ROMs), pois catalisa a redução de peróxido de hidrogênio $\left(\mathrm{H}_{2} \mathrm{O}_{2}\right)$ e hidroperóxidos lipídicos (Ganther, 1979), impedindo que o $\mathrm{H}_{2} \mathrm{O}_{2}$ forme o radical hidroxila (HO'), que é um ROM altamente lesivo para as estruturas biológicas. A defesa antioxidante contra o $\mathrm{H}_{2} \mathrm{O}_{2}$ somente será completa sob a ação da catalase e,ou, da Se-GPx ${ }^{\text {ase }}$ (Bianchi \& Antunes, 1999).

Desse modo, a suplementação de zinco e selênio podem amenizar os efeitos deletérios desencadeados pelo estresse de calor em frangos de corte, uma vez que esses animais podem apresentar um padrão antioxidante reduzido. Além disso, tradicionalmente, na ração de frangos de corte, o zinco e o selênio são utilizados na forma inorgânica como sulfatos, óxidos e carbonatos e, mais recentemente, pesquisas estão sendo realizadas para in- vestigar a utilização da forma quelatada, por esta apresentar maior biodisponibilidade.

Outra resposta, em animais mantidos sob estresse de calor, é o aumento da concentração sanguínea de malondialdeído (MDA). Este é um subproduto da peroxidação lipídica, a qual se inicia quando há uma produção no organismo dos (ROM), também conhecidos como radicais livres, embora nem todos os ROM sejam efetivamente radicais livres. Essas reações são deletérias ao organismo animal e são desencadeadas em condições de estresse oxidativo; entretanto, podem ser controladas por sistemas antioxidantes, em especial os minerais zinco e selênio.

Por essas razões, este estudo foi realizado para avaliar os efeitos da suplementação de zinco e selênio nas formas orgânica e inorgânica sobre o desempenho, na peroxidação lipídica e no rendimento de carcaça em frangos de corte, de 15 a 42 dias de idade, submetidos a estresse cíclico de calor.

\section{MATERIAL E MÉTODOS}

Foram utilizados 2.400 pintos de corte machos, da linhagem CobbAvian48TM com um dia de idade, alojados em um galpão convencional, que continha 80 boxes de 2,00 $\mathrm{m}$ de comprimento, 1,60 $\mathrm{m}$ de largura e $0,90 \mathrm{~m}$ de altura, e forrado com palha de arroz como cama. Para cada quatro boxes, foi utilizada uma campânula a gás (Big Clímax ${ }^{\circledR}$ ) como fonte de aquecimento para os pintos.

$\mathrm{O}$ delineamento adotado foi inteiramente casualizado, em esquema fatorial $2 \times 5$, sendo dois ambientes (conforto térmico e estresse cíclico de calor) e cinco níveis de suplementação: [S1) ração controle; S2) S1 + 40 mg/kg de Zn inorgânico; S3) S1 + 40 mg/kg de Zn orgânico; S4) S1 + $40 \mathrm{mg} / \mathrm{kg}$ de Zn inorgânico e $0,2 \mathrm{mg} /$ kg de selênio orgânico e S5) S1 + 40 mg/kg de Zn orgânico e $0,2 \mathrm{mg} / \mathrm{kg}$ de selênio orgânico], totalizando dez tratamentos com oito repetições e 30 animais por unidade experimental (Boxe). Nas dietas basais, foram utilizadas $250 \mu$ de selênio inorgânico e $60 \mathrm{mg}$ de zinco inorgânico, e, o selênio e o zinco orgânicos na forma de leveduras. 
O galpão foi dividido ao meio, longitudinalmente, com cortinas plásticas para equalização de dois ambientes: 1) ambiente controle - com temperatura de conforto térmico controlada por cortinas, ventiladores e nebulizadores para garantir a zona de termoneutralidade das aves conforme idade, 2) ambiente aquecido ciclicamente - de um a 14 dias em temperatura ambiente termoneutra e depois em ambiente aquecido por meio de campânulas a gás durante 12 horas (de sete às 19 horas) de forma cíclica, sendo $1 \mathrm{~h} 30 \mathrm{~m}$ de calor e $1 \mathrm{~h} 30 \mathrm{~min}$ sem aquecimento. A temperatura neste ambiente aquecido foi de $38{ }^{\circ} \mathrm{C}$ do $15^{\circ}$ ao $28^{\circ}$ dia, e de $40{ }^{\circ} \mathrm{C}$ do $29^{\circ}$ ao $42^{\circ}$ dia.

A temperatura ambiente e umidade do ar foram continuamente monitoradas com termômetro de máxima e mínima (0 a $\left.50{ }^{\circ} \mathrm{C}\right)$ (Incoterm $\left.{ }^{\circledR}\right)$ e psicrômetro (Incoterm ${ }^{\circledR}$ ), respectivamente, colocados em cinco pontos do galpão. Os frangos foram divididos em dois grupos: um criado em conforto térmico e outro sob temperatura ambiente cíclica elevada por 12 horas diárias.

As rações foram formuladas, utilizando níveis nutricionais elaborados e formulados com base em Rostagno (2005) e NRC (1994). Os ingredientes foram submetidos à análise bromatológica para verificar sua composição, de acordo com o Compêndio Brasileiro de Alimentação Animal (SINDIRAÇÕES, 2005) (Tabela 1).
O programa alimentar consistiu em três fases: ração pré-inicial (300 g/ave), inicial (900 g/ave) e crescimento (2.500 g/ave). As aves receberam ração e água potável $a d$ libitum em um programa de 24 horas de luz por dia.

No primeiro e $42^{\circ}$ dia de idade, todas as aves foram pesadas para obtenção do ganho de peso. $\mathrm{O}$ consumo de ração foi calculado considerando-se a quantidade de ração fornecida e as sobras nos comedouros. A conversão alimentar foi calculada pela relação entre o consumo de ração e o ganho de peso das aves também aos 42 dias de idade.

A peroxidação lipídica foi avaliada em duas épocas (21 e 42 dias de idade), pela dosagem dos produtos reativos ao ácido tiobarbitúrico (TBARS), principalmente o malondialdeído (MDA), subproduto da lipoperoxidação que reage com duas moléculas de ácido tiobarbitúrico e produz um complexo de coloração avermelhada (Rumley \& Paterson, 1998). As amostras de sangue foram coletadas de uma ave por boxe por punção da veia braquial em tubos a vácuo (Vacuntainer ${ }^{\circledR}$ ), contendo EDTA como anticoagulante. Após, foram submetidas a dois ciclos de congelamento (15 minutos) e descongelamento (cinco minutos), com a finalidade de romper as membranas celulares e promover liberação das enzimas antioxidantes. O descongelamento foi feito

Tabela 1: Composição percentual e valor nutricional das dietas experimentais

\begin{tabular}{lccc}
\hline Ingredientes & Pré-inicial & Inicial & Crescimento \\
\hline Sorgo $(8,6 \%$ de PB) & 53,7 & 56,41 & 60,77 \\
Farelo de soja (46,5\% de PB) & 38,5 & 33,61 & 28,58 \\
Óleo de soja & 3,76 & 5,86 & 6,76 \\
Fosfato bicálcico & 1,77 & 1,81 & 0,98 \\
Calcário & 0,95 & 0,96 & 0,44 \\
Sal comum & 0,45 & 0,44 & 0,29 \\
DL-metionina & 0,33 & 0,31 & 0,24 \\
L-lisina HCL & 0,25 & 0,28 & 0,20 \\
Suplemento vitamínico e mineral inicial* & 0,20 & 0,20 & 0,09 \\
Suplemento vitamínico e mineral crescimento** & - & - & 0,88 \\
L-treonina & 0,07 & 0,09 & 3,20 \\
Composição Nutricional & & & 0,42 \\
Cálcio & 0,95 & 0,95 & 1,10 \\
Energia metabolizável (Mcal/kg) & 2,96 & 3,10 & 0,80 \\
Fósforo disponível & 0,45 & 0,45 & 19,00 \\
Lisina digestível & 1,30 & 1,20 & 0,21 \\
Metionina+cistina digestível & 0,95 & 0,90 & 0,70 \\
Proteína bruta & 23,00 & 21,00 & 0,22 \\
Sódio & 0,22 & 0,21 & \\
Treonina digestível & 0,78 & 0,73 & \\
Triptofano digestível & 0,24 & 0,23 & \\
\hline
\end{tabular}

* MC-Mix Frango Inicial 2 kg (®M-Cassab Comércio e Indústria Ltda) - Composição por quilo de ração: Vit A 11.000UI; D3 2.000UI; Ácido Fólico $400 \mu \mathrm{g}$; Pantotenato de cálcio 10 mg; Biotina $60 \mu \mathrm{g}$; Niacina 35 mg; Piridoxina 2 mg; Riboflavina 4,5 mg; Tiamina 1,2 mg; B12 16 g; K 1,5 mg; Se 250 g; Cu 9 mg; Zn 60 mg; I 1 mg; Fe 30 mg; Mn 60 mg; Colina 249 mg; Promotor 384 mg; Coccidiostático 375 mg; Antioxidante 120 mg.

** MC-Mix Frango Crescimento 2kg (®M-Cassab Comércio e Indústria Ltda)-Composição por quilo de ração: Vit A $9.000 U I$; D3 1.600UI; E 14 mg;

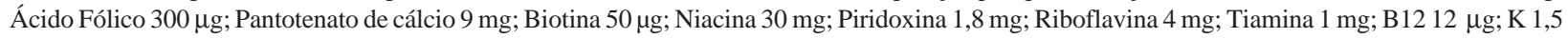
mg; Se 250 g; Cu 9 mg; Zn 60 mg; I 1 mg; Fe 30 mg; Mn 60 mg; Colina 219 mg; Promotor 385 mg; Coccidiostático 550 mg; Antioxidante 120 mg. 
em banho-maria a $37^{\circ} \mathrm{C}$. Em seguida, foram centrifugadas a 1300 x $g$ por dois minutos, para separação do plasma. Foram pipetados $500 \mu \mathrm{L}$ do plasma e adicionados a $1000 \mu \mathrm{L}$ de ácido tricloroacético a 10\%. Após homogeneização e outra centrifugação a 1300 x $g$ por 15 minutos a $15{ }^{\circ} \mathrm{C}$, foram pipetados $500 \mu \mathrm{L}$ do sobrenadante. Após adição de $500 \mu \mathrm{L}$ de ácido tiobarbitúrico (TBA) a 1\% (dissolvido em hidróxido de sódio a $0,05 \mathrm{M}$ ) a aquele volume de sobrenadante, os tubos foram incubados em água fervente $\left(100{ }^{\circ} \mathrm{C}\right)$ durante dez minutos e, em seguida, foram resfriados sob água corrente por cinco minutos.

A concentração molar de TBARS foi determinada a partir dos valores de absorvância (A) dessas soluções em 532 nm e obtida pela equação derivada da expressão matemática da lei de Lambert-Beer $(\mathrm{A}=\varepsilon$.c.l $)$; onde $\varepsilon$ é o coeficiente de extinção molar $\left(\mathrm{M}^{-1} \cdot \mathrm{cm}^{-1}\right)$ dos TBARS em $532 \mathrm{~nm}$ e 1 é o caminho óptico $(1 \mathrm{~cm})$ percorrido na solução. Essa análise foi executada no Laboratório de Enzimologia, do Instituto de Genética e Bioquímica da Universidade Federal de Uberlândia.

A temperatura cloacal foi medida com termômetro clínico veterinário (Incoterm ${ }^{\circledR}$ ) com precisão de $0,1{ }^{\circ} \mathrm{C}$, em duas aves por boxe, às $17 \mathrm{~h}$, com inserção do termômetro $3 \mathrm{~cm}$ na cloaca aos $14^{\circ}, 21^{\circ}, 28^{\circ}, 35^{\circ}$ e $42^{\circ}$ dias de idade.

$\mathrm{O}$ rendimento de carcaça foi avaliado aos 42 dias. Duas aves por boxe (16 por tratamento, totalizando 160) com o peso corporal próximo da média $( \pm 100 \mathrm{~g}$ de variação) foram selecionadas e abatidas. Estas aves foram retiradas e marcadas individualmente com lacre plástico numerado em cada pé, para a sua identificação. Após a pesagem, os animais foram mantidos em boxes sem ração para um jejum alimentar de oito horas e hídrico de quatro horas, antes de serem abatidas.

No abate dos frangos com $42^{\circ}$ de idade, foram avaliados os parâmetros relativos ao rendimento de carcaça e de cortes. Foram avaliados os pesos das aves vivas, das carcaças evisceradas (não resfriadas em "chiller") e dos cortes (peito com e sem osso, asa, coxa + sobrecoxa, pé + cabeça + pescoço e dorso)

Os dados foram avaliados pela análise de variância e as médias comparadas pelo teste de Tukey a 5\%.

\section{RESULTADOS E DISCUSSÃO}

Os níveis de suplementação de zinco e selênio não influenciaram as medidas de desempenho aos 42 dias de idade (Tabela 2). Entretanto, aves estressadas pelo calor apresentaram menor consumo de ração que aquelas em conforto térmico, com queda de 11,31\% (Tabela 2). Este resultado era esperado uma vez que animais sob estresse de calor reduzem a ingestão de alimentos na tentativa de obter o equilíbrio térmico, ou seja, diminuir a produção metabólica de calor. Resultados concordantes com os obtidos por Faria Filho et al. (2007) que observaram em frangos de corte estressados por calor $\left(32{ }^{\circ} \mathrm{C}\right)$ menor consumo (26\%) comparados aos criados a $22{ }^{\circ} \mathrm{C}$ e também Ribeiro et al. (2008). É importante ressaltar que não somente a temperatura ambiente elevada, mas também as diferenças na magnitude, duração e tipo de estresse a que as aves são submetidas são importantes fatores a serem considerados. Outro aspecto observado por Teeter et al. (1992) é que aves em estresse cíclico pelo calor comem menos durante os horários críticos de pico de calor e consomem mais alimentos nas horas mais frescas do dia.

A exposição ao estresse cíclico de calor resultou em $4,6 \%$ de redução no ganho de peso (Tabela 2). Em temperaturas mais elevadas, as aves ingerem menor quantidade da ração e, como consequência, têm o ganho de peso reduzido. Este resultado concorda com os de Ribeiro et al. (2008), que obtiveram redução de $6 \%$ quando submeteram as aves ao estresse cíclico de calor, porém por menor período ( 21 a 42 dias de idade). Oliveira Neto et al. (2000) observaram que a temperatura ambiente influenciou o ganho de peso, que foi $16 \%$ menor em temperaturas elevadas. Lana et al. (2000) também encontraram redução de $15 \%$ no ganho de peso de aves estressadas pelo calor $\left(31^{\circ} \mathrm{C}\right)$ em relação àquelas mantidas em conforto térmico $\left(23{ }^{\circ} \mathrm{C}\right)$.

A temperatura ambiente e os níveis de suplemento não influenciaram a conversão alimentar (Tabela 2). Lana et al. (2000) também não encontraram alteração na conversão alimentar em frangos de corte mantidos a temperatura de $31^{\circ} \mathrm{C}$. Igualmente, Quinteiro-Filho et al. (2010) não observaram piora na conversão alimentar quando frangos de corte foram criados dos 35 aos 41 dias de idade sob estresse cíclico de calor $\left(31{ }^{\circ} \mathrm{C}\right.$ por dez horas diária), entretanto, encontraram piora neste parâmetro no grupo que foi exposto a $36^{\circ} \mathrm{C}$ por dez horas diária dos 35 aos 41 dias de idade.

Não houve efeito do ambiente, dos suplementos minerais, da idade e da interação entre esses fatores sobre a concentração plasmática de TBARS (Tabela 3). Esses resultados contrariam aqueles reportados por Lin et al. (2006), que verificaram a indução de estresse oxidativo em frangos de corte criados sob estresse de calor durante três horas por dia a partir de cinco semanas de idade, à temperatura de $32{ }^{\circ} \mathrm{C}$.

Essa divergência pode ser explicada em parte pela quantidade de zinco e selênio utilizados no suplemento mineral da dieta basal, ou seja, a suplementação convencional de selênio e zinco inorgânicos foi suficiente para protegê-las de danos oxidativos não sendo necessário adicionar minerais acima do habitual. 
Aos $35^{\circ}$ e $42^{\circ}$ dia de idade, as aves criadas sob estresse cíclico de calor apresentaram valores de temperatura cloacal superiores às criadas em conforto térmico (Tabela 4). Este resultado pode ser explicado pela dificuldade da ave em dissipar calor durante exposição à temperatura ambiente elevada. Segundo Furlan (2006), o resfriamento evaporativo respiratório constitui-se em um dos mais importantes meios de perda de calor das aves em temperaturas elevadas. Este autor afirma que isto ocorre porque as aves têm a capacidade de aumentar a frequência respiratória em até dez vezes e, desta forma, aumentar a perda de calor via trato respiratório. No entanto, o aumento na frequência respiratória gera mais energia, produzindo mais calor, podendo determinar os quadros de hipertermia severo em frangos de corte.

Marchini et al. (2007) também verificaram que frangos de corte após serem submetidos ao estresse cíclico de calor $\left(38^{\circ} \mathrm{C}\right.$ do primeiro ao $27^{\circ}$ dia de idade e à $40^{\circ} \mathrm{C}$ do $28^{\circ}$ ao $42^{\circ}$ dia de idade, por uma hora diária) apresentaram valores de temperatura cloacal superiores àquelas mantidas em termoneutralidade. Altan et al. (2000), na mesma situação, observaram elevação da temperatura cloacal em aves mantidas em estresse pelo calor. Segundo Menten et al. (2006), em condições de temperatura e umidade elevadas, as aves podem desencadear um aumento de $4,7^{\circ} \mathrm{C}$ na temperatura cloacal. Ainda, Han et al. (2010) verificaram maior temperatura corporal em frangos de corte expostos por três horas à temperatura de $35^{\circ} \mathrm{C}$ em relação aos não submetidos ao calor.

Neste estudo, aves mantidas sob estresse cíclico de calor apresentaram menor peso vivo aos 42 dias de idade independentemente do suplemento mineral (Tabela 5). Este resultado era esperado e pode ser explicado, em parte, pelo fato de os frangos estressados por calor

Tabela 2: Desempenho de frangos de corte, aos 42 dias de idade, criados, ou não, sob estresse cíclico de calor e suplementados com zinco e selênio

\begin{tabular}{|c|c|c|c|c|c|c|}
\hline \multirow{2}{*}{ Ambiente ${ }^{* * *}$} & \multicolumn{2}{|c|}{ Consumo de ração } & \multicolumn{2}{|c|}{ Ganho de peso } & \multicolumn{2}{|c|}{ Conversão Alimentar } \\
\hline & (kg) & $\mathrm{CV}(\%)$ & (kg) & $\mathrm{CV}(\%)$ & (kg/kg) & $\mathrm{CV}(\%)$ \\
\hline $\mathrm{C}$ & $4,86 \mathrm{a}$ & 12,35 & $3,03 \mathrm{a}$ & 3,30 & 1,41 & 0,71 \\
\hline EC & $4,31 b$ & 6,96 & $2,89 b$ & 3,46 & 1,39 & 0,72 \\
\hline \multicolumn{7}{|c|}{ Suplementos* } \\
\hline $\mathrm{S} 1$ & 4,52 & 9,29 & 2,95 & 4,07 & 1,4 & 4,29 \\
\hline $\mathrm{S} 2$ & 4,44 & 6,76 & 2,92 & 6,16 & 1,4 & 2,86 \\
\hline S3 & 4,59 & 16,34 & 2,98 & 4,36 & 1,39 & 5,04 \\
\hline S4 & 4,75 & 10,95 & 3 & 4,00 & 1,42 & 3,52 \\
\hline S5 & 4,64 & 13,15 & 2,96 & 6,08 & 1,41 & 5,67 \\
\hline
\end{tabular}

*Suplementos: S1- ração controle (premix mineral comercial); S2- S1 + 40 mg/kg de Zn inorgânico; S3- S1 + 40 mg/kg de Zn orgânico; S4- S1 + 40 mg/ $\mathrm{kg}$ de $\mathrm{Zn}$ inorgânico e $0,2 \mathrm{mg} / \mathrm{kg}$ de selênio orgânico; e S5- S1 + $40 \mathrm{mg} / \mathrm{kg}$ de Zn orgânico e 0,2 mg/kg de selênio orgânico.

** Diferenças significantes $(\mathrm{P}<0.05)$ quando comparadas pelo teste de Tukey.

Tabela 3: Concentrações sanguíneas (nM) de substâncias reativas ao ácido tiobarbitúrico (TBARS) em frangos de corte criados sob estresse cíclico pelo calor e suplementação com zinco e selênio

\begin{tabular}{|c|c|c|c|c|c|}
\hline \multirow{3}{*}{ Suplementos* } & \multirow{3}{*}{ Ambientes } & \multicolumn{4}{|c|}{ Idade (dias)** } \\
\hline & & \multicolumn{2}{|c|}{21} & \multicolumn{2}{|c|}{42} \\
\hline & & $\mathbf{n M}$ & $\mathrm{CV}(\%)$ & $\mathbf{n M}$ & $\mathrm{CV}(\%)$ \\
\hline \multirow{2}{*}{ S1 } & $\mathrm{C}$ & 56,6 & 85,8 & 35,1 & $1.231,3$ \\
\hline & $\mathrm{EC}$ & 119,4 & 181,9 & 79,3 & 53,8 \\
\hline \multirow{2}{*}{$\mathrm{S} 2$} & $\mathrm{C}$ & 58,5 & 207,8 & 161,9 & 163,5 \\
\hline & $\mathrm{EC}$ & 106,6 & 40,1 & 85,7 & 57,2 \\
\hline \multirow{2}{*}{$\mathrm{S} 3$} & $\mathrm{C}$ & 81,9 & 127,4 & 165,8 & 198,4 \\
\hline & $\mathrm{EC}$ & 80,9 & 71,4 & 63,4 & 94,4 \\
\hline \multirow{2}{*}{ S4 } & $\mathrm{C}$ & 48,8 & 118,8 & 66,3 & 166,2 \\
\hline & $\mathrm{EC}$ & 88,9 & 68,5 & 128,2 & 159,3 \\
\hline \multirow{2}{*}{ S5 } & $\mathrm{C}$ & 48,8 & 169,4 & 91,7 & 100,9 \\
\hline & $\mathrm{EC}$ & 74,5 & 62,1 & 163,5 & 120,3 \\
\hline
\end{tabular}

* Suplementos nutricionais (S): S1- Ração controle (suplemento mineral comercial); S2- S1 + 40 mg/kg de Zn inorgânico; S3- S1 + 40 mg/kg de Zn orgânico; S4- S1 + 40 mg/kg de Zn inorgânico e 0,2 mg/kg de selênio orgânico e S5- S1 + 40 mg/kg de Zn orgânico e 0,2 mg/kg de selênio orgânico.

** Diferenças não significantes $(\mathrm{P}>0.05)$ quando comparadas pelo teste de Tukey. 
Tabela 4: Temperatura cloacal, em ${ }^{\circ} \mathrm{C}$, de frangos de corte criados sob condições de ambiente natural [controle (C)] e estresse cíclico de calor [(EC)] de 15 a 42 dias de idade, suplementados com zinco e selênio

\begin{tabular}{|c|c|c|c|c|c|c|c|c|c|c|}
\hline \multirow{2}{*}{ Ambiente } & \multicolumn{2}{|c|}{14} & \multicolumn{2}{|c|}{21} & \multicolumn{2}{|c|}{28} & \multicolumn{2}{|c|}{35} & \multicolumn{2}{|c|}{42} \\
\hline & ${ }^{\circ} \mathbf{C}$ & $\overline{C V(\%)}$ & ${ }^{\circ} \mathbf{C}$ & $\operatorname{CV}(\%)$ & ${ }^{\circ} \mathbf{C}$ & $\mathrm{CV}(\%)$ & ${ }^{\circ} \mathbf{C}$ & $\overline{\mathrm{CV}(\%)}$ & ${ }^{\circ} \mathbf{C}$ & $\mathrm{CV}(\%)$ \\
\hline $\mathrm{C}$ & 41,2 & 1,2 & 41,5 & 0,4 & 41,5 & 0,7 & $41 \mathrm{a}$ & 0,5 & $41,8 \mathrm{a}$ & 0,7 \\
\hline $\mathrm{EC}$ & 41,8 & 1,4 & 41,4 & 0,7 & 42 & 1,2 & $42,4 b$ & 1,4 & $43,0 \mathrm{~b}$ & 1,8 \\
\hline \multicolumn{11}{|c|}{ Suplementos* } \\
\hline S1 & $41,6 \mathrm{a}$ & 1,2 & $41,6 \mathrm{a}$ & 0,7 & $41,7^{\mathrm{a}}$ & 0,9 & $41,9 a$ & 1,4 & $42,5 \mathrm{a}$ & 2,1 \\
\hline S2 & $41,4 \mathrm{a}$ & 1,4 & $41,6 \mathrm{a}$ & 0,7 & $41,6^{\mathrm{a}}$ & 0,9 & $41,9 a$ & 1,4 & $42,4 \mathrm{a}$ & 1,9 \\
\hline S3 & $41,4 \mathrm{a}$ & 1,6 & $41,6 \mathrm{a}$ & 0,7 & $41,7^{\mathrm{a}}$ & 1,2 & $42,0 \mathrm{a}$ & 1,6 & $42,5 \mathrm{a}$ & 2,1 \\
\hline S4 & $41,6 \mathrm{a}$ & 1,2 & $41,6 \mathrm{a}$ & 0,7 & $41,6^{\mathrm{a}}$ & 0,9 & $41,9 a$ & 1,2 & $42,2 \mathrm{a}$ & 1,9 \\
\hline S5 & $41,5 \mathrm{a}$ & 1,7 & $41,6 a$ & 0,9 & $41,9^{\mathrm{a}}$ & 1,6 & $42,1 \mathrm{a}$ & 2,1 & $42,5 \mathrm{a}$ & 2,3 \\
\hline
\end{tabular}

*Suplementos nutricionais (S): S1- Ração controle (Premix mineral comercial); S2- S1 + 40 mg/kg de Zn inorgânico; S3- S1 + 40mg/kg de Zn orgânico; S4- S1 + 40 mg/kg de Zn inorgânico e 0,2 mg/kg de selênio orgânico e S5- S1 + 40 mg/kg de Zn orgânico e 0,2 mg/kg de selênio orgânico.

Médias na coluna com letras iguais não diferem $(\mathrm{P}>0.05)$ pelo teste de Tukey.

Tabela 5: Características de carcaça de frangos de corte submetidos, ou não, a estresse cíclico de calor e suplementados com zinco e selênio

\begin{tabular}{|c|c|c|c|c|c|c|c|}
\hline & \multicolumn{7}{|c|}{ Suplementos* } \\
\hline & Ambiente ${ }^{* *}$ & $\mathbf{S 1} * * *$ & $\mathbf{S} 2 * * *$ & S3*** & $\mathbf{S} 4 * * *$ & S5*** & Média \\
\hline \multirow{3}{*}{ Peso Vivo (kg) } & $\mathrm{C}$ & $2.984 \mathrm{a}$ & $3.063 \mathrm{a}$ & $3.025 \mathrm{a}$ & $3.015 \mathrm{a}$ & $3.056 \mathrm{a}, \mathrm{C}$ & 3.029 \\
\hline & $\mathrm{EC}$ & $2.889 \mathrm{~b}$ & $2.913 b$ & $2.867 \mathrm{~b}$ & $2.984 \mathrm{~b}$ & $2.936 b, \mathrm{D}$ & 2.917 \\
\hline & Média & 2.935 & 2.988 & 2.943 & 3.000 & 2.996 & \\
\hline \multirow{3}{*}{ Carcaça Eviscerada $(\mathrm{kg})$} & $\mathrm{C}$ & $2.292 \mathrm{C}$ & $2.382 \mathrm{a}, \mathrm{D}$ & $2.368 \mathrm{a}, \mathrm{E}$ & $2.307 \mathrm{a}, \mathrm{F}$ & $2.203 \mathrm{a}, \mathrm{G}$ & 2.311 \\
\hline & $\mathrm{EC}$ & 2.274 & $2.291 b$ & $2.275 b$ & $2.206 \mathrm{~b}$ & $2.292 b$ & 2.268 \\
\hline & Média & 2.282 & 2.337 & 2.320 & 2.258 & 2.247 & \\
\hline \multirow{3}{*}{ Carcaça Eviscerada (\%) } & $\mathrm{C}$ & $76,79 a$ & 77,74 & 78,14 & $76,30 \mathrm{a}$ & 77,82 & 77,35 \\
\hline & $\mathrm{EC}$ & $78,95 b$ & 79,25 & 79,34 & $79,35 \mathrm{~b}$ & 78,69 & 79,11 \\
\hline & Média & 77,90 & 78,45 & 78,74 & 77,77 & 78,24 & \\
\hline \multirow{3}{*}{ Carcaça Sem PCP (\%) } & $\mathrm{C}$ & $68,39 a$ & 68,75 & 70,11 & $68,49 \mathrm{a}$ & 69,87 & 69,11 \\
\hline & EC & $70,27 b$ & 70,38 & 70,74 & $70,97 \mathrm{~b}$ & 70,44 & 70,56 \\
\hline & Média & 69,36 & 69,54 & 70,43 & 69,69 & 70,15 & \\
\hline \multirow{3}{*}{$\mathrm{PCP}(\%)$} & $\mathrm{C}$ & 10,98 & 11,54 & 10,22 & 10,24 & 10,57 & 10,71 \\
\hline & $\mathrm{EC}$ & 10,98 & 11,15 & 10,84 & 10,55 & 10,47 & 10,50 \\
\hline & Média & 10,98 & 11,35 & 10,53 & 10,39 & 10,52 & \\
\hline \multirow{3}{*}{ Peito com osso (\%) } & $\mathrm{C}$ & $33,64 \mathrm{a}$ & 32,59 & 32,99 & 33,35 & 33,79 & 33,26 \\
\hline & $\mathrm{EC}$ & $35,63 b$ & 32,58 & 32,08 & 33,20 & 33,09 & 33,55 \\
\hline & Média & 34,67 & 32,62 & 33,04 & 33,28 & 33,43 & \\
\hline \multirow{3}{*}{ Peito sem osso (\%) } & $\mathrm{C}$ & 23,51 & 22,39 & 23,20 & 23,50 & 23,98 & 23,31 \\
\hline & $\mathrm{EC}$ & 22,72 & 22,41 & 22,72 & 23,06 & 22,85 & 22,75 \\
\hline & Média & 23,10 & 22,40 & 22,96 & 23,29 & 23,43 & \\
\hline \multirow{3}{*}{ Sobrecoxas e coxas $(\%)$} & $\mathrm{C}$ & 29,25 & 28,95 & 28,99 & 28,20 & 28,97 & 29,09 \\
\hline & $\mathrm{EC}$ & 29,81 & 29,76 & 29,80 & 29,83 & 29,33 & 29,72 \\
\hline & Média & 29,54 & 29,34 & 29,39 & 29,55 & 29,17 & \\
\hline \multirow{3}{*}{ Asas (\%) } & $\mathrm{C}$ & 9,56 & 10,09 & 9,91 & 9,94 & 10,28 & 9,96 \\
\hline & EC & 9,38 & 9,87 & 9,95 & 10,05 & 10,16 & 9,87 \\
\hline & Média & 9,47 & 9,98 & 9,62 & 9,99 & 10,23 & \\
\hline \multirow{3}{*}{ Dorso (\%) } & $\mathrm{C}$ & $16,56 \mathrm{a}$ & 16,82 & $17,87 \mathrm{~b}$ & 17,17 & 16,40 & 16,97 \\
\hline & $\mathrm{EC}$ & $14,19 b, C$ & $16,58 \mathrm{D}$ & $16,33 b, \mathrm{E}$ & $16,37 \mathrm{~F}$ & $16,95 \mathrm{G}$ & 16,05 \\
\hline & Média & 15,34 & 16,70 & 17,10 & 16,79 & 16,66 & \\
\hline
\end{tabular}


apresentarem menor consumo de alimentos em relação aos criados sob conforto térmico. Além disso, AbuDieyeh (2006) afirmou que a temperatura ambiente elevada pode induzir a mudanças fisiológicas, tal como digestão ineficiente e falhas no metabolismo.

O ambiente e os níveis de suplemento não alteraram o rendimento de peito com e sem osso, sobrecoxa + coxa e asas (Tabela 5). Entretanto, aves em estresse cíclico de calor apresentaram redução no peso da carcaça eviscerada, o que era esperado, pois reduziram tanto o consumo de ração quanto seu ganho de peso (Rosa et al., 2007).

Existem resultados conflitantes sobre a influência do zinco sobre o desempenho de aves estressadas. Os resultados obtidos concordam com os de Bartlett \& Smith (2003) que não encontraram efeito sobre o desempenho em frangos de corte estressados pelo calor e suplementados com zinco.

\section{CONCLUSÕES}

Não se identificou a necessidade de suplementar zinco orgânico e inorgânico e selênio orgânico acima da suplementação convencional em frangos de corte estressados ciclicamente pelo calor.

\section{REFERÊNCIAS}

Abu-Dieyeh ZHM (2006) Effect of high temperature per se on growth performance of broilers. International Journal of Poultry Science, $5: 19-21$.

Altan Ö, Altan A, Oguz, I, Oguz I, Pabuçcuoglu A \& Konyalioglu S (2000) Effects of heat stress on growth, some blood variables and lipid oxidation in broilers exposed to high temperature at an early age. British Poultry Science, 41:489-493.

Bartlett JR \& Smith MO (2003) Effects of different levels of zinc on the performance and immunocompetence of broilers under heat stress. Poultry Science, 82:1580-1588.

Bianchi MLP \& Antunes LMG (1999) Radicais livres e os principais antioxidantes da dieta. Revista de Nutrição, 12:123-130.

Borges AS, Maiorka A \& Silva AVF (2003) Fisiologia do estresse calórico e a utilização de eletrólitos em frangos de corte. Ciência Rural, 33:975981.

Daniels LA (1996) Selenium metabolism and bioavailability. Biological trace element research, 54:185-199.

Faria Filho DE, Campos DMB, Torres KAA, Vieira BS, Rosa PS, Vaz AM, Macari M \& Furlan RL (2007) Protein levels for heat-exposed broilers: performance, nutrients digestibility, and energy and protein metabolism. International Journal of Poultry Science, 6:187-194.

Furlan RL (2006) Influência da temperatura na produção de frangos de corte. In: $7^{\circ}$ Simpósio Brasil Sul de Avicultura, Chapecó. Anais, EMBRAPA/CNPSA. p.104-135.

Ganther HE (1979) Metabolism of hydrogen selenide and methylated selenides. Advances in nutritional research, 2:107-128.

Han AY, Zhang MH, Zuo XL, Zheng SS, Zhao CF, Feng JH \& Cheng C (2010) Effect of acute heat stress on calcium concentration, proliferation, cell cycle, and interleukin-2 production in splenic lymphocytes from broiler chickens. Poultry Science, 89:2063-2070.
Hellmeister Filho P, Menten JFM, Da Silva MAN, Coelho AAD \& Savino VJM (2003) Efeito de genótipo e do sistema de criação sobre o desempenho de frangos tipo caipira. Revista Brasileira de Zootecnia, 32:1883-1889.

Lana GRQ, Rostagno HS, Albino LFT \& Lana AMQ (2000) Efeito da temperatura ambiente e da restrição alimentar sobre o desempenho composição da carcaça de frangos de corte. Revista Brasileira de Zootecnia, 29:1117-1123.

Lin H, Decuypere E \& Buyse J (2006) Acute heat stress induces oxidative stress in broiler chickens. Comparative biochemistry and physiology. Part A. Molecular and integrative physiology, 144:01-17.

Marchini CFP, Silva PL, Nascimento MRBM \& Tavares M (2007) Frequência respiratória e temperatura cloacal em frangos de corte submetidos à temperatura ambiente cíclica elevada. Archives of Veterinary Science, 12:41- 46.

Marchini CFP, Silva PL, Nascimento MRBM, Beletti ME, Silva NM \& Guimarães EC (2011) Body Weight, Intestinal Morphometry and Cell Proliferation of Broiler Chickens Submitted to Cyclic Heat Stress. International Journal of Poultry Science, 10:455-460.

Menten JFM, Barbosa Filho JAD, Silva MAN, Silva IJO, Racanicci AMC, Coelho AAD \& Savino VJM (2006) Physiological responses of Broiler chicken to pre slaughter heat stress. In: XII European Poultry Conference, Verona. Book of Abstrats, World's Poultry Science Journal. p. 254.

NRC - National Research Council (1994) Nutrient requirements of Poultry. Washington, National Academy Press. 381p.

Oliveira Neto RA, Oliveira MFR, Donzele LJ, Rostagno HS, Ferreira RA, Maximiano HC \& Gasparino E (2000) Efeito da temperatura ambiente sobre o desempenho e características de carcaça de frangos de corte alimentados com dieta controlada e dois níveis de energia. Revista Brasileira de Zootecnia, 29:183-190.

Quinteiro-Filho WM, Ribeiro A, Ferraz-de-Paula V, Pinheiro ML, Sakai M, Sá LRM, Ferreira AJP \& Palermo-Neto J (2010) Heat stress impairs performance parameters, induces intestinal injury, and decreases macrophage activity in broiler chickens. Poultry Science, 89:19051914.

Ribeiro AML, Vogt LK, Canal CW, Laganá C \& Streck AF (2008) Suplementação de vitaminas e minerais orgânicos e sua ação sobre a imunocompetência de frangos de corte submetidos a estresse por calor. Revista Brasileira de Zootecnia, 37:636-644.

Rosa OS, Faria Filho DE, Dahlke F, Vieira BS, Macari M \& Furlan RL (2007) Performance and carcass characteristics of broiler chickens with different growth potential and submitted to heat stress. Brazilian Journal of Poultry Science, 9:181-186.

Rostagno SH (2005) Composição de Alimentos e Exigências Nutricionais de Aves e Suínos. $3^{\mathrm{a}}$ ed. Viçosa, UFV. 61p.

Rumley AG \& Paterson JR (1998) Analytical aspects of antioxidants and free radical activity in clinical biochemistry. Annals of Clinical Biochemistry, 35:181-200.

Sahin K, Sahin N, Kucuk O, Hayirli A \& Prasad AS (2009) Role of dietary zinc in heat-stressed poultry: A review. Poultry Science, 88:21762183.

Compêndio Brasileiro de Alimentação Animal (2005) Guia de Métodos Analíticos. In: Compêndio Brasileiro de Alimentação Animal. São José do Rio Preto, Sindirações. p.01-204.

Teeter RG, Smith MO \& Wiernusz CJ (1992) Broiler acclimation to the heat distress and feed intake effects on body temperature in birds exposed to thermoneutral and high ambiental temperatures. Poultry Science, 71:1101-1104. 